\title{
Atividade antifúngica, in vitro, do óleo de café verde
}

\author{
Antifungal activity, in vitro, of the green coffee oil
}

\author{
Virgínia Guerra Elizei1 *, Sara Maria Chalfoun', Deila Magna dos Santos Botelho', Pedro Paulo Reis Rebelles²
}

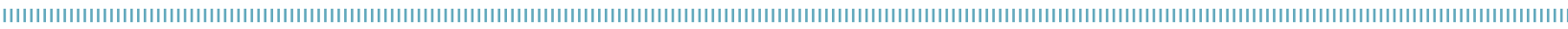

RESUMO: O objetivo deste trabalho foi avaliar o efeito do contato direto e da fração volátil do óleo de café verde, testado nas concentraçôes de 500, 1.000, 1.500 e $2.000 \mu \mathrm{L} \mathrm{L}^{-1}$, sobre o crescimento micelial e a esporulação dos fungos Penicillium roqueforti e Rhizopus stolonifer. O óleo essencial de cravo-da-índia na concentração de $800 \mu \mathrm{L} \mathrm{L}^{-1}$ foi utilizado para comparação. Nas concentraçóes de 1.500 e $2.000 \mu \mathrm{L} \mathrm{L}^{-1}$, o óleo de café verde em contato direto proporcionou redução da esporulação do fungo $R$. stolonifer, sendo estatisticamente semelhante ao óleo de cravo-da-índia. Na fração volátil do óleo de café verde, observou-se redução significativa da esporulaçáo de $P$. roqueforti e $R$. stolonifer na concentraçáo de 2.000 $\mu \mathrm{L} \mathrm{L}^{-1}$. O óleo de café verde, em contato direto ou por volatilizaçáo, reduziu significativamente o crescimento micelial e a esporulação de ambos os fungos em comparaçáo com a testemunha.

PALAVRAS-CHAVE: Penicillium roqueforti; Rhizopus stolonifer; óleo de cravo-da-índia.

\begin{abstract}
The objective of this study was to evaluate the effect of direct contact and volatile fraction of from green coffee oil, tested at concentrations of 500,1,000,1,500 and $2,000 \mu \mathrm{L} \mathrm{L}^{-1}$, on mycelial growth and sporulation of Penicillium roqueforti and Rhizopus stolonifer. The essential oil of clove at a concentration of $800 \mu \mathrm{L} \mathrm{L}^{-1}$ was used for comparison. At concentrations of 1,500 and $2,000 \mu \mathrm{L} \mathrm{L}^{-1}$, the green coffee oil in direct contact caused a reduction of sporulation for $R$. stolonifer, similar to clove oil. In the volatile fraction of the green coffee oil, there was a significant reduction in sporulation of $P$. roqueforti and $R$. stolonifer at a concentration of $2,000 \mu \mathrm{L} \mathrm{L}^{-1}$. The green coffee oil, in direct contact or by volatilization, significantly reduced the mycelial growth and sporulation of both fungi compared to the control.
\end{abstract}

KEYWORDS: Penicillium roqueforti; Rhizopus stolonifer; oil clove. 
O fungo Penicillium roqueforti, comumente encontrado em silagem e grãos, pode produzir diversas micotoxinas, como roquefortina $\mathrm{C}$, isofumigaclavina $\mathrm{A}$ e $\mathrm{B}$, toxina $\mathrm{PR}$ e ácido micofenólico, que podem causar tanto perdas econômicas quanto afetar a saúde humana (CHitarra et al., 2003). Adicionalmente, o fungo Rhizopus stolonifer (Ehrenb: Fr). Vuill, agente causal da podridão pós-colheita em diversos legumes e frutas (STEvens et al., 2004; Zhang et al., 2007), também é responsável por expressivas perdas econômicas no setor agrícola. Os tratamentos comumente utilizados para controle de fungos em alimentos são os tratamentos térmicos ou químicos (SAmson et al., 1995; Pitt; Hoching, 1997). Com isso, a procura por novos agentes antimicrobianos, a partir de plantas, é intensa devido à resistência dos microrganismos diante de produtos sintéticos (Araújo, 2005).

O uso intensivo de agroquímicos para controlar doenças em plantas e frutos vem causando prejuízos ao meio ambiente e selecionando espécies de fungos com resistência a fungicidas. Isso justifica, portanto, a busca por métodos alternativos de controle, no qual se incluem o controle biológico e a indução de resistência em plantas pelo uso de extratos vegetais e óleos essenciais, entre outros (Stangarlin et al., 1999; Schwan-Estrada; StANGarlin, 2005).

Diversos estudos têm comprovado o efeito de extratos e óleos essenciais de plantas medicinais quanto a sua capacidade de controlar doenças em plantas, tanto por sua atividade antimicrobiana direta quanto indireta (CHAO; Young, 2000; Fiori et al., 2000; Bastos; AlbuQuerque, 2004).

O óleo de café verde é constituído por triacilgliceróis (75\%), matéria insaponificável $(13,54 \%)$ e ceras $(0,24 \%)$ (Wagemaker et al., 2012). Esse óleo possui propriedades cosméticas (Speer; Kolling-Speer, 2006), com efeitos antioxidantes e antimicrobianos avaliados em formulaçóes cosméticas (Wagemaker et al., 2012). Contudo, estudos da atividade antimicrobiana desse óleo em fungos de importância agrícola são escassos. Dessa forma, a presente pesquisa teve como objetivo avaliar o efeito in vitro do óleo de café verde em dois métodos de aplicaçáo (efeito volátil e contato direto) sobre o crescimento micelial e a esporulação dos fungos $P$. roqueforti e $R$. stolonifer.

As sementes de cafeeiro (Coffea arabica L.), cultivar Mundo Novo 376-4, utilizadas para obtenção do óleo de café foram obtidas na Fazenda Experimental de Três Pontas (MG) pertencente à Empresa Agropecuária de Minas Gerais (EPAMIG). O óleo essencial de café verde foi obtido por prensagem hidráulica e foi filtrado por membranas Millipore ${ }^{\circ}$. As concentraçóes testadas foram de 0, 500, 1.000, $1.500 \mathrm{e}$ $2.000 \mu \mathrm{L} \mathrm{L}^{-1}$. O óleo essencial de cravo-da-índia na concentração de $800 \mu \mathrm{L} \mathrm{L}^{-1}$ foi usado como tratamento padrão, uma vez que sua eficácia foi comprovada no controle de Penicillium spp. (Souza et al., 2004).
Para a avaliação do efeito de contato, as diluiçôes do óleo formam feitas diretamente em $100 \mathrm{~mL}$ de meio de cultura BDA. Uma alíquota de $100 \mu \mathrm{L}$ de suspensão de esporos, de cada fungo estudado, padronizada para a concentração de $10^{6}$ esporos $\mathrm{mL}^{-1}$, foi adicionada ao meio de cultura, sendo a mistura homogeneizada e posteriormente vertida em placas de Petri de $9 \mathrm{~cm}$ de diâmetro.

O teste de princípios ativos voláteis às diluiçôes do óleo de café verde foi realizado em álcool etílico hidratado de cereais nas concentraçôes de 500, 1.000, 1.500 e $2.000 \mu \mathrm{L} \mathrm{L}^{-1}$. Foram utilizados discos de papel de filtro esterilizados $(5 \mathrm{~mm}$ de diâmetro), os quais foram embebidos nas soluçóes de óleo de café verde diluído nas concentraçôes citadas e colocados na tampa das placas de Petri. Posteriormente, as placas foram vedadas utilizando filme plástico para impedir que os princípios voláteis dos óleos fossem perdidos. O álcool de cereais, utilizado na diluição do óleo, foi testado como controle negativo. As placas de ambos os experimentos foram incubadas em estufa BOD a $24 \pm 1^{\circ} \mathrm{C}$ com fotoperíodo de 12 horas pelo período de 7 dias.

Para a avaliação do crescimento micelial $(\mathrm{cm} / \mathrm{dia})$, foram realizadas mediçôes do diâmetro das colônias, em dois eixos perpendiculares entre si, aos sete dias após a instalação do experimento.

A quantificação da esporulação dos fungos, também realizada aos 7 dias após a instalação do experimento, foi realizada com a raspagem das colônias com pincel $(15 \mathrm{~mL}$ de água destilada esterilizada/placa), filtragem em gaze esterilizada e quantificação dos conídios obtidos utilizando câmara de Neubauer.

O experimento para verificar o efeito de contato direto do óleo de café verde foi instalado em delineamento inteiramente casualizado, com 6 tratamentos (óleo de café verde nas concentrações de $0,500,1.000,1.500$ e 2.000 $\mu \mathrm{L} \mathrm{L}^{-1}$ e óleo essencial de cravo-da-índia na concentração de $800 \mu \mathrm{L} \mathrm{L}^{-1}$ ) e 4 repetiçóes, sendo cada placa de Petri considerada uma unidade experimental. Para avaliaçáo do efeito da fração volátil do óleo, o delineamento utilizado foi o inteiramente casualizado, com 7 tratamentos (óleo de café verde nas concentraçóes de $0,500,1.000,1.500$ e $2.000 \mu \mathrm{L} \mathrm{L}^{-1}$, óleo essencial de cravo-da-índia na concentração de $800 \mu \mathrm{L} \mathrm{L}^{-1}$ e álcool de cereais) e 4 repetições. As análises foram feitas usando o pacote estatístico Sistema de Análise de Variância para Dados Balanceados - Sisvar, e as medias foram comparadas pelo teste Scott \& Knott a $5 \%$ de significância.

Não se observou efeito de contato direto do óleo de café verde sobre a inibição do desenvolvimento micelial de ambos os fungos testados. Contudo, a ação do óleo reduziu significativamente a esporulação tanto do fungo P. roqueforti quanto do fungo R. stolonifer (Figs. 1A e 1B). O óleo de cravo-da-índia na concentração de $800 \mu \mathrm{L} \mathrm{L}^{-1}$ apresentou redução de $95 \%$ na esporulaçáo do fungo $P$. roqueforti, sendo o tratamento 
mais eficaz. A concentração de $2.000 \mu \mathrm{L} \mathrm{L}^{-1}$ do óleo de café foi a mais efetiva, dentre as concentraçóes testadas, apresentando redução na esporulação de $63 \%$, quando comparada ao tratamento controle (Fig. 1A). As demais concentraçóes testadas diferiram somente do tratamento controle.

A esporulaçáo do fungo $R$. stolonifer foi significativamente reduzida nos tratamentos com a aplicação do óleo de café verde nas concentraçóes de 1.500 e $2.000 \mu \mathrm{L} \mathrm{L}^{-1}$ e óleo de cravo-da-índia, sendo os tratamentos mais eficazes (Fig. 1B). Costa et al. (2011) constataram que o óleo essencial de cravo-da-índia apresentou atividade fungicida na concentração de $0,15 \%$ sobre o crescimento de $R$. solani, F. oxysporum e $F$ solani. A avaliação microscópica dos micélios dos fungos evidenciou diversas alteraçóes morfológicas, como presença de vacúolos, desorganização dos conteúdos celulares, diminuição na nitidez da parede celular, intensa fragmentação e menor turgência das hifas.

Com relação ao efeito da fração volátil do óleo de café verde, observou-se que, assim como efeito de contato direto, somente a esporulaçáo foi influenciada pela aplicação dos

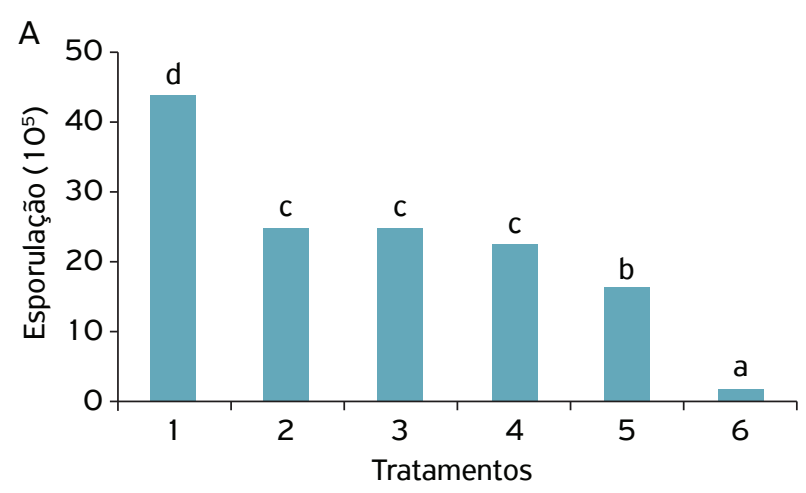

B

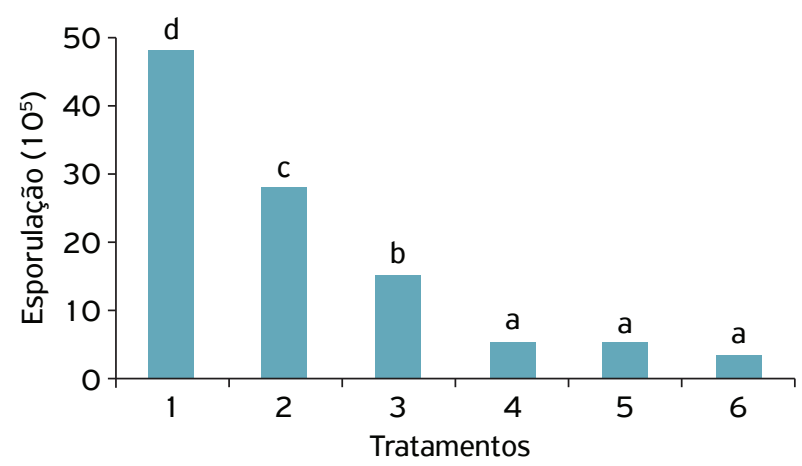

Figura 1. Efeito do óleo de café verde misturado ao meio de cultura (contato direto) na redução da esporulação de Penicillium roqueforti (A) e Rhizopus stolonifer (B). Tratamentos: 1) controle; 2) óleo de café verde (OC) $500 \mu \mathrm{L} \mathrm{L}^{-1}$; 3) OC $1.000 \mu \mathrm{L} \mathrm{L}^{-1}$; 4) OC $1.500 \mu \mathrm{L} \mathrm{L}^{-1}$; 5) OC $2.000 \mu \mathrm{L} \mathrm{L}^{-1}$; 6) óleo essencial de cravo-da-índia $800 \mu \mathrm{L} \mathrm{L}^{-1}$. Letras distintas representam diferença significativa entre os tratamentos pelo teste de Scott-Knott a 5\% de probabilidade. óleos. Para o fungo $P$. roqueforti, observou-se redução da variável estudada somente para a maior concentração testada de óleo de café verde, $2.000 \mu \mathrm{L} \mathrm{L}^{-1}$, náo diferindo do óleo de cravo-da-índia (Fig. 2A). As concentraçôes de 1.000 e $1.500 \mu \mathrm{L} \mathrm{L}^{-1}$ apresentaram efeito semelhante ao controle negativo (álcool de cereais). Assim como observado para o fungo $P$. roqueforti, o óleo de café verde na concentração de $2.000 \mu \mathrm{L} \mathrm{L}^{-1}$ reduziu significativamente a esporulaçáo do fungo $R$. stolonifer, sendo semelhante à aplicação do óleo de cravo-da-índia (Fig. 2B).

Durante a extração do óleo de café verde, compostos fenólicos possivelmente foram extraídos juntamente. Os ácidos clorogênicos e compostos relacionados são os principais componentes da fração fenólica dos grãos de café verde, alcançando teores de até $14 \%$ (em massa de matéria seca) (Farah; Donangelo, 2006). Nas plantas, os ácidos clorogênicos e outros compostos fenólicos participam de uma série de funçôes biológicas, como na resistência a pragas e doenças, resposta à seca e proteção contra a radiação solar (Mondolot et al., 2006).
A

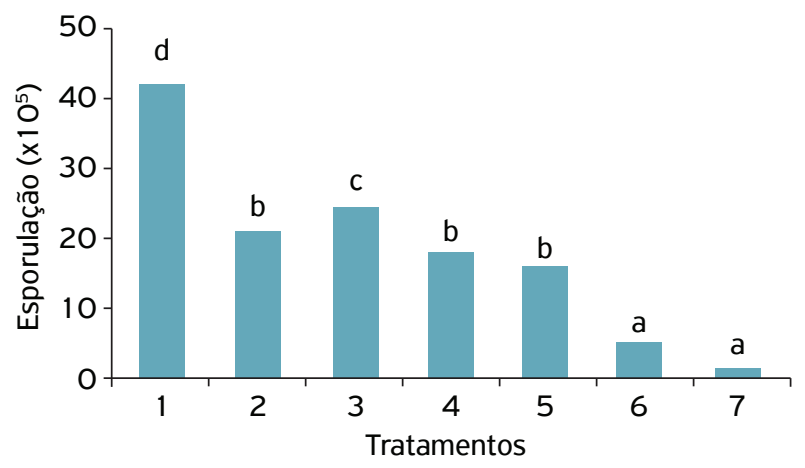

B

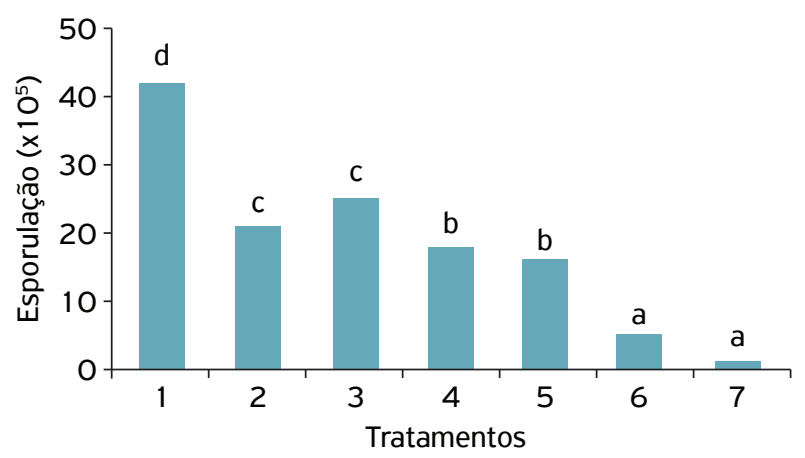

Figura 2. Efeito da fração volátil do óleo de café verde na redução da esporulação de Penicillium roqueforti (A) e Rhizopus stolonifer (B). Tratamentos: 1) controle; 2) álcool; 3) óleo de café verde (OC) $500 \mu \mathrm{L} \mathrm{L}^{-1}$; 4) OC $1.000 \mu \mathrm{L} \mathrm{L}^{-1}$; 5) OC $\left.1.500 \mu \mathrm{L} \mathrm{L} \mathrm{L}^{-1} ; 6\right) \mathrm{OC} 2.000 \mu \mathrm{L} \mathrm{L}^{-1}$; 7) óleo essencial de cravoda-índia $800 \mu \mathrm{L} \mathrm{L}^{-1}$. Letras distintas representam diferença significativa entre os tratamentos pelo teste de Scott-Knott a $5 \%$ de probabilidade. 
ARAÚJO, R.C.Z. Embalagens ativas com ervas aromáticas e condimentos na conservação de pães artesanais. 2005. $45 \mathrm{f}$. Dissertação (Mestrado em Ciência dos Alimentos) - Universidade Federal de Lavras, Lavras, 2005.

BARA, M.T.F.; AMARAL, M.F.Z.J. Avaliação da atividade antifúngica de extratos de plantas sobre o crescimento de fitopatógenos. Revista Eletrônica de Farmácia Suplemento, v.2, p.5-8, 2005.

BASTOS, C.N.; ALBUQUERQUE, P.S.B. Efeito do óleo de Piper aduncum no controle em pós-colheita de Colletotrichum musae em banana. Fitopatologia Brasileira, v.29, n.5, p.555-557, 2004.

CHAO, S.C.; YOUNG, D.G. Screening for inhibitory activity of essential oils ou selected bacteria, fungi and viruses. Journal Essentials Oil Research, v.12, n.4, p.630-649, 2000.

CHITARRA, G.S.; BREEUWER, P.; NOUT, M.J.; van AELST, A.C.; ROMBOUTS, F.M.; ABEE, T.. An antifungal compound produced by Bacillus subtilis YM 10-20 inhibits germination of Penicillium roqueforti conidiospores. Journal of Applied Microbiology, v.94, p.159-166, 2003.

COSTA, A.R.T.; AMARAL, M.F.Z.J.; MARTINS, P.M.; PAULA, J.A.M.; FIUZA, T.S.; TRESVENZOL, L.M.F.; PAULA, J.R.; BARA, M.T.F. Ação do óleo essencial de Syzygium aromaticum (L.) Merr. \& L.M.Perry sobre as hifas de alguns fungos fitopatogênicos. Revista Brasileira de Plantas Medicinais, v.13, n.2, p.240-245, 2011.

FARAG, R.S.; DAW, Z.Y.; ABO-RAYA, S.H. Influence of Some Spice Essential Oils on Aspergillus Parasiticus Growth and Production of Aflatoxins in a Synthetic Medium. Journal of Food Science, v.54, n.1, p.54-74, 1989.

FARAH, A.; DONANGELO, C.M. Phenolic compounds in coffee. Brazilian Journal of Plant Physiology, v. 18, p. 1, p.23-36, 2006.

FIORI, A.C.G; SCHWAN-ESTRADA, K.R.F.; STANGARLIN, J.R.; VIDA, J.B.; SCAPIM, C.A.; CRUZ, M.E.S.; PASCHOLATI, S.F. Antifungal activity of leaf extracts and essential oils of some medicinal plants against Didymella bryoniae. Journal Phytopathology, v. 148, n.78, p.483-487, 2000.

MONDOLOT, L.; LA FISCA, P.; BUATOIS, B.; TALANSIER, E.; DE KOCHKO, A.; CAMPA, C. Evolution in caffeoylquinic acid content and histolocalization during coffea canephora leaf development. Annals of Botany, v.98, p.33-40, 2006.

PITT, J.I.; HOCHING, A.D. Fungi and food spoilage. London: Blackie Academic and Professional; 1997.

SAMSON, R.A.; HOEKSTRA, E.S.; FRISVAD, J.C.; FILTENBORG, O. Introduction to food-borne fungi. Baarn, the Netherlands: Centraalbureau voor Schimmelcultures; 1995.

SCHWAN-ESTRADA, K.R.F.; STANGARLIN, J.R. Extratos e óleos essenciais de plantas medicinais na indução de resistência. In: CAVALCANTI, L.S; DI PIERO, R.M.; CIA, P.; PASCHOLATI, S.F.; RESENDE, M.L.V.; ROMEIRO, R.S. (Ed.). Indução de resistência em plantas a patógenos e insetos. Piracicaba: Fealq; 2005. p. $125-132$.

SOUZA, S.M.C.; PEREIRA, M.C.; ANGÉLICO, C.L.; PIMENTA, C.J. Avaliação de óleos essenciais de condimentos sobre o desenvolvimento micelial de fungos associados a produtos de panificação. Ciência e Agrotecnologia, v.28, n.3, p.685-690, 2004.

SPEER, K.; KOLLING-SPEER. The lipid fraction of the coffee bean. Brazilian Journal of Plant Physiology, v.18, n.1, p.201216, 2006.

STANGARLIN, J.R.; SCHWAN-ESTRADA, K.R.F.; CRUZ, M.E.S.; NOZAKI, M.H. Plantas medicinais e controle alternativo de fitopatógenos. Biotecnologia Ciência \& Desenvolvimento, v.2, n. 11 , p.16-24, 1999.

STEVENS, C.; LIU, J.; KHAN, V.A.; LU, J.Y.; KABWE, M.K.; WILSON, C.L. The effects of low-dose ultraviolet light-C treatment on polygalacturonase activity, delay ripening and Rhizopus soft rot development of tomatoes. Crop Protection, v.23, p.551555, 2004.

WAGEMAKER, T.A.L.; FERNANDES, A.S.; CAMPOS, P.M.; RODRIGUES, L.M.; RIJO, P. Evaluation of antioxidant and antimicrobial activities of green coffee oil in cosmetic formulations. Biomedical and Biopharmaceutical Research Journal, v.9, n.2, p.207-214, 2012.

ZHANG, Y.; BAO, F.; HU, J.; LIANG, S.; ZHANG, Y; DU, G; ZHANG, C.; CHENG, Y. Antibacterial lignans and triterpenoids from Rostellularia procumbens. Planta Medica, v.73, n. 15, p.1596-1599, 2007. 